\title{
Affect- and role-based loyalty to supervisors in Chinese organizations
}

\author{
Ding-Yu Jiang ${ }^{1}$ and Bor-Shiuan Cheng $^{2}$ \\ ${ }^{1}$ Department of Psychology, National Chung-Cheng University, and ${ }^{2}$ Department of Psychology, National Taiwan Uni- \\ versity, Taipei, Taiwan \\ A study conducted in a Taiwanese financial services company revealed that affect- and role-based loyalty are two \\ distinct types of loyalty to supervisors. The ethical behaviour of supervisors, perceived supervisor support, \\ interpersonal justice, and respect for hierarchy predicted affect-based loyalty, whereas only interpersonal justice \\ and respect for hierarchy predicted role-based loyalty to the supervisor. Affect-based loyalty had a more positive \\ correlation with supervisory satisfaction than did role-based loyalty, and role-based loyalty had a more positive \\ correlation with extra-role performance and attendance than did affect-based loyalty.
}

Key words: affect-based loyalty to supervisor, Chinese organizations, loyalty to supervisor, role-based loyalty to supervisor.

\section{Introduction}

Loyalty to supervisors is important in organizations, and especially in Chinese organizations, because supervisors in these organizations sometimes evaluate their subordinates' effectiveness, make promotion decisions, and assign challenging tasks according to how loyal the subordinates are to their supervisors (Silin, 1976; Redding, 1990; Cheng, Farh, Chang, \& Hsu, 2002). There are several reasons why subordinates in Chinese organizations are loyal to their supervisor. For example, employees may feel obligated by their role to remain loyal to their supervisor. We refer to this type of loyalty as role-based loyalty. Alternatively, employees may remain loyal to their supervisor because they have an emotional attachment to their supervisor. We refer to this type of loyalty as affect-based loyalty. The first objective of the current study was to identify these two types of loyalty in a Chinese organization. The second objective was to explore some predictors and outcomes of these two types of loyalty.

\section{Affect- and role-based loyalty}

Affect-based loyalty results from an emotional bond with the supervisor, and is related to the construct of commitment to the supervisor, although they are not identical constructs (Becker, Billings, Eveleth, \& Gilbert, 1996; Cheng, Jiang, \& Riley, 2003; Stinglhamber \& Vandenberghe, 2003). Commitment to the supervisor has a strong affective

Correspondence: Bor-Shiuan Cheng, Department of Psychology, National Taiwan University, No. 1, Sec. 4. Roosevelt Road, Taipei, 10617, Taiwan. Email: chengbor@ntu.edu.tw

Received 9 March 2005; accepted for publication 22 August 2007. component, and is derived from organizational commitment (Stinglhamber \& Vandenberghe, 2003). In the current study, we used commitment to the supervisor as a form of affect-based loyalty to the supervisor.

Loyalty to the supervisor in a Chinese organization may also be motivated by role obligations. Role-based loyalty to the supervisor refers to the degree to which subordinates feel obligated by their social role to remain loyal to their supervisor. Chinese culture emphasizes the fulfilment of social role expectations in a specific social context, such as the filial piety of children towards their parents in the family context and the loyalty of subordinates to their supervisors in the workplace (Hwang, 1999). Subordinates who express loyalty to their supervisor are fulfilling a social role expectation (Biggart \& Hamilton, 1983). Social roles help to maintain order and structure in the society (Hamilton, 1995), and subordinates are socialized to express loyalty to their supervisors in a manner appropriate to the workplace (Hwang, 1999; Cheng et al., 2003). Studies have shown that subordinates in Chinese organizations are often expected to be loyal to their supervisor (Redding, 1990; Hofstede, 2001; Wong \& Huang, 2003).

Although affect- and role-based loyalty to the supervisor are conceptually distinct constructs, no known studies have examined this conceptual distinction empirically. The current study sought to fill this void by examining the different correlates of these two types of loyalty.

\section{Predictors and outcomes of affect-based loyalty}

According to social identity theory, subordinates tend to identify with supervisors who possess valued positive 
attributes (Sluss \& Ashforth, 2007). In addition, subordinates are also likely to internalize the valued positive attributes of their supervisors (O'Reilly \& Chatman, 1986). One such positive attribute is the supervisor's ethical standards. A supervisor who displays ethical behaviour helps subordinates to develop trust, commitment, and positive interpersonal relationships in the workplace (Elangovan \& Shapiro, 1998; Schminke, Ambrose, \& Neubaum, 2005). Thus, a supervisor's ethical behaviour should be a predictor of the affect-based loyalty of subordinates. Consequently, the first hypothesis is as follows.

Hypothesis 1: Supervisor ethical behaviour is positively associated with affect-based loyalty.

Social exchange theory maintains that perceived supervisor support is another important predictor of affect-based loyalty (Eisenberger, Stinglhamber, Vandenberghe, Sucharski, \& Rhoades, 2002). Perceived supervisor support is defined as the extent to which subordinates perceive their supervisor to be concerned with their benefits and appreciative of their contribution (Kottke \& Sharafinski, 1988). When subordinates feel that their supervisor readily provides individualized support, they will reciprocate by being loyal. Therefore, the second hypothesis in this study is as follows.

Hypothesis 2: Perceived supervisor support is positively associated with affect-based loyalty.

With respect to the possible outcomes of affect-based loyalty, several studies have shown that affect-based loyalty is related to supervisory satisfaction, intention to leave, job performance, and organizational citizenship behaviour (Chen, Tsui, \& Farh, 2002; Cheng et al., 2003; Stinglhamber \& Vandenberghe, 2003). However, these studies did not examine the possible outcomes of rolebased loyalty. According to Cox (1993), there are two categories of outcome variables: attitudinal-based outcomes and performance-based outcomes. Attitudinal-based outcomes, such as intention to leave and supervisory satisfaction, are employee attitudes; performance-based outcomes, such as job performance and organizational citizenship behaviour, are the actual behaviours displayed by employees. Affect-based loyalty represents a strong positive attitude towards the supervisor-subordinate relationship. Thus, compared with role-based loyalty, affectbased loyalty should have a stronger relationship with attitudinal outcomes. Therefore, the following hypotheses are proposed.

Hypothesis 3a: Compared with role-based loyalty, affectbased loyalty is more positively associated with supervisory satisfaction.

Hypothesis 3b: Compared with role-based loyalty, affectbased loyalty is more negatively associated with intention to leave.

\section{Predictors and outcomes of role-based loyalty}

Role-based loyalty is emphasized in Chinese culture. In Chinese organizations, employees are often taught to behave appropriately and to perform their social roles appropriately (Farh \& Cheng, 2000), including fulfilling role expectations and obligations during interpersonal interactions (Shore et al., 2004). In Chinese organizations, the supervisor is expected to treat subordinates well, and the subordinates are expected to reciprocate with loyalty (Farh $\&$ Cheng, 2000). Interpersonal justice perception represents the extent to which subordinates perceive that they are being treated fairly by their supervisor (Greenberg, 2006). Therefore, we present the following hypothesis.

Hypothesis 4: Interpersonal justice perception is positively associated with role-based loyalty.

Traditionality, or the extent to which an employee adheres to traditional Chinese culture, has been shown to be an important predictor of Chinese employee behaviour (Spreitzer, Perttula, \& Xin, 2005). One of the dimensions of traditionality is respect for hierarchy. This dimension is closely related to workplace attitudes and behaviour (Yang, 1998; Spreitzer et al., 2005). A subordinate's respect for hierarchy represents an acceptance and acknowledgement of the hierarchical nature of the superior-subordinate relationship (Yang, 1998). Employees with a high degree of respect for authority tend to show their loyalty to authority (Redding, 1990). Thus, these employees may view loyalty to their supervisor as an obligation. Accordingly, respect for hierarchy should have a significant association with rolebased loyalty. Thus, we present the following hypothesis. Hypothesis 5: Respect for hierarchy is positively associated with role-based loyalty.

There are few studies of the possible outcomes of rolebased loyalty and other role-related behaviour in Chinese organizations. According to the definition of role-based loyalty, subordinates exhibit loyalty to their supervisors because they feel that they are personally obligated to do so and are willing to follow the behavioural expectations associated with their role as an employee. Accordingly, subordinates with strong role-based loyalty are likely to display in-role behaviour (Biggart \& Hamilton, 1983), such as displaying better job performance, extra-role performance, and attendance. Extra-role performance, which is also known as organizational citizenship behaviour, refers to discretionary behaviour that is not explicitly codified in a formal organizational reward system, but that nevertheless has an important influence on organizational effectiveness (Podsakoff, Mackenzie, Paine, \& Bachrach, 2000). Thus, we propose the following hypotheses.

Hypothesis 6a: Compared with affect-based loyalty, rolebased loyalty is more positively associated with job performance. 
Hypothesis 6b: Compared with affect-based loyalty, rolebased loyalty is more positively associated with attendance.

Hypothesis 6c: Compared with affect-based loyalty, rolebased loyalty is more positively associated with extra-role performance.

In summary, in the current study, we sought to differentiate between two types of loyalty to the supervisor in Chinese organizations, and to identify some of the predictors and possible outcomes of the two types.

\section{Method}

\section{Participants and procedures}

The participants were 1339 employees (out of 3600) from a large privately owned Taiwanese commercial bank. Of the participants, $51.3 \%$ were male and $48.7 \%$ female. Their age distribution was as follows: $3.1 \%$ were below 25 years old, $17.1 \%$ between 26 and $30,32.3 \%$ between 31 and 35 , $28.9 \%$ between 36 and $40,12.2 \%$ between 41 and 45, $4.8 \%$ between 46 and 50, and $1.6 \%$ over 50. Most of the participants had completed a 4-year college education $(60.0 \%)$. Others had completed a senior high school education, a two-year college education (32.7\%), or a postgraduate degree $(5.8 \%)$. The participants filled out a questionnaire, most completing it in groups under the supervision of the researchers. About 100 questionnaires were mailed to participants who could not attend the group sessions. The participants sent back the completed questionnaire directly to the researchers using a return envelope with prepaid postage that was attached to the questionnaire.

\section{Measures}

Supervisory satisfaction, job performance, intention to leave, and attendance were measured using a scale that ranged from 0 (very low) to 100 (very high), and the other variables were measured using a five-point Likert-type scale that ranged from 1 (strongly disagree) to 5 (strongly agree).

Affect- and role-based loyalty. The measure of affectbased loyalty was taken from the supervisory commitment scale developed by Cheng et al. (2003). The measure for role-based loyalty was a new measure. Based on the definition of role-based loyalty and past studies on loyalty in Chinese societies (Cheng \& Jiang, 2000), three role-based loyalty items were generated. The responses to the two scales from half of the participants (randomly selected) were subjected to an exploratory factor analysis. A twofactor solution was extracted after considering the scree plot. Table 1 shows that the two loyalty measures formed separate factors. The internal consistency coefficient (Cronbach's $\alpha$ ) was 0.86 for the affect-based loyalty measure and 0.67 for the role-based loyalty measure. The two factors had a moderate correlation of 0.27 .

The responses from the remaining participants were subjected to a confirmatory factor analysis (EQS Version 6.1). The two-factor solution had a better fit to the data $\left(\chi^{2}=171.32\right.$, df $=19 ; \quad \mathrm{CFI}=0.93 ; \mathrm{GFI}=0.94 ; \mathrm{SRMR}=$

Table 1 Exploratory factor analysis of the affect- and role-based loyalty measures $(N=687)$

\begin{tabular}{|c|c|c|c|c|}
\hline Item & $M$ & $S D$ & $\begin{array}{l}\text { Affect-based } \\
\text { loyalty to } \\
\text { supervisor }\end{array}$ & $\begin{array}{l}\text { Role-basec } \\
\text { loyalty to } \\
\text { supervisor }\end{array}$ \\
\hline $\begin{array}{l}\text { 1. Since starting this job, my personal values and those of my supervisor have } \\
\text { become more similar. }\end{array}$ & 3.10 & 0.88 & 0.90 & -0.07 \\
\hline 2. My values and those of my supervisor are similar. & 2.89 & 0.82 & 0.88 & -0.09 \\
\hline $\begin{array}{l}\text { 3. I praise my current supervisor in front of my friends as a great supervisor to work } \\
\text { with. }\end{array}$ & 3.56 & 0.98 & 0.82 & 0.03 \\
\hline $\begin{array}{l}\text { 4. The reason why I prefer my current supervisor to others is because of what } \\
\text { he/she stands for, that is, his/her values. }\end{array}$ & 3.33 & 0.95 & 0.75 & -0.02 \\
\hline 5. When someone praises my supervisor, I feel like it is a personal compliment. & 3.68 & 0.97 & 0.66 & 0.25 \\
\hline $\begin{array}{l}\text { 6. Being a subordinate, I have an obligation to perform well and let my supervisor } \\
\text { be free of worries. }\end{array}$ & 4.53 & 0.55 & -0.12 & 0.88 \\
\hline 7. I do my assigned work well and efficiently; this is what a subordinate should do. & 4.55 & 0.57 & -0.03 & 0.83 \\
\hline $\begin{array}{l}\text { 8. Being a subordinate, I am willing to sacrifice personal time to accomplish tasks } \\
\text { my supervisor assigned to me. }\end{array}$ & 3.99 & 0.78 & 0.24 & 0.60 \\
\hline Eigenvalues & & & 3.63 & 1.61 \\
\hline Total variance explained $(\%)$ & & & 45.36 & 20.07 \\
\hline Cumulative total variance explained (\%) & & & 45.36 & 65.43 \\
\hline
\end{tabular}

Analysis method: Principal component method with oblimin rotation. 
0.08; RMSEA $=0.11)$ than the one-factor model $\left(\chi^{2}=448.74, \mathrm{df}=20 ; \mathrm{CFI}=0.80 ; \mathrm{GFI}=0.85 ; \mathrm{SRMR}=\right.$ 0.12 ; RMSEA $=0.18$ ). Both the exploratory and confirmatory factor analyses showed that affect- and role-based loyalty are separate constructs.

Predictors. Supervisor ethical behaviour was measured using a five-item scale adopted from the moral leadership scale of Cheng, Chou, Huang, Wu, and Farh (2004). The items described the ethical behaviour of supervisors, for example, 'My supervisor acts as a good role model at work' and 'My supervisor seeks revenge in the name of the public interest when he/she is offended' (reverse coded). The internal consistency coefficient for this scale was 0.91 .

The measure of interpersonal justice perception was adopted from the interpersonal justice scales used in past studies (Bies \& Moag, 1986; Folger \& Bies, 1989; Colquitt, 2001). The measure had four items; sample items are 'When making decisions, my supervisor considers my limitations and the difficulties involved' and 'My supervisor listens to my opinions.' The internal consistency coefficient for this scale was 0.79 .

The perceived supervisor support measure was adopted from the perceived supervisor support scale of Eisenberger et al. (2002). The scale has four items; sample items are 'My supervisor respects my personal goals and values' and 'My supervisor provides me with important work-related information needed to accomplish an assigned task.' The internal consistency coefficient for this scale was 0.84 .

Respect for hierarchy was measured using three items taken from the traditionality scale of Yang, Yu, and Yeh (1991). Sample items are 'When people are in dispute, they should ask the most senior person to decide who is right' and 'Obeying authorities and respecting superiors are good virtues and should be acquired by everyone.' The internal consistency coefficient for this scale was 0.66 .

Outcome variables. Job performance was measured by the four-item scale of Cheng et al. (2003). Sample items are 'How would your supervisor rate your quality of work? In other words, is your work perfect, free of error, and highly accurate?' and 'Compared to your coworkers, how would you rate your work performance?' The internal consistency coefficient of this scale was 0.85 .

We measured extra-role performance with five items selected from the Chinese Organizational Citizenship Behaviour Scale developed by Farh, Earley, and Lin (1997). The selected items had factor loadings on and content validity for the target dimension. Sample items are 'Assist new coworkers in adjusting to the work' and 'Looking for other work to do when finishing assigned work.' The internal consistency coefficient for this scale was 0.69 . Supervisory satisfaction, intention to leave, and attendance were measured using a single item taken from Cheng et al. (2003), which was 'In general, how satisfied are you with your supervisor?'

\section{Results}

Table 2 lists the means, standard deviations, and zero-order correlations for the variables included in the current study. Table 3 lists the partial correlations and path coefficients between the loyalty measures and the other variables. Figure 1 illustrates the path analysis results. The fitness indices indicated a good model fit $\left(\chi^{2}=66.12, \mathrm{df}=18\right.$; $\mathrm{CFI}=0.99 ; \mathrm{GFI}=0.99 ;$ SRMR $=0.02 ; \mathrm{RMSEA}=0.05$ ). The association between perceived supervisor support and supervisory satisfaction, and that between supervisor ethical behaviour and supervisory satisfaction were included in the model to improve the model fit. These unpredicted associations suggest that perceived supervisor support and supervisor ethical behaviour were both indirectly (through loyalty to supervisors) and directly associated with supervisory satisfaction.

As hypothesized, supervisor ethical behaviour and perceived supervisor support predicted affect-based loyalty only, whereas interpersonal justice perception and respect for hierarchy predicted role-based loyalty. Interpersonal justice perception and respect for hierarchy also predicted affect-based loyalty, and these predictive relationships, although not hypothesized, suggest that employees who perceived their relationship with their supervisor to be fair and had a greater respect for authority were more emotionally committed to their supervisor.

To examine the hypothesized relationship between loyalty and each of the outcome variables, two strategies were used. First, we determined whether the partial correlation between a loyalty measure and the outcome variable (controlling for the other loyalty measure) was significantly different from the partial correlation between the other loyalty measure and the outcome variable. Second, we applied EQS and constrained the paths linking the two loyalty measures to the outcome variable to be of equal strength. The constraint was then removed. By examining the chi-squared change or difference in the path model as a result of removing the constraint, we were able to determine whether the two path coefficients had equal strength. When the chi-squared difference test was significant, the two path coefficients had significantly different strengths (Schmacker \& Lomax, 2004).

As hypothesized, both the partial correlation and path analyses results indicated that supervisory satisfaction had a significantly stronger association with affect-based loyalty than with role-based loyalty. Intention to leave had a significantly stronger association with affect-based loyalty than with role-based loyalty in the partial correlation analysis, but was associated equally strongly with both 

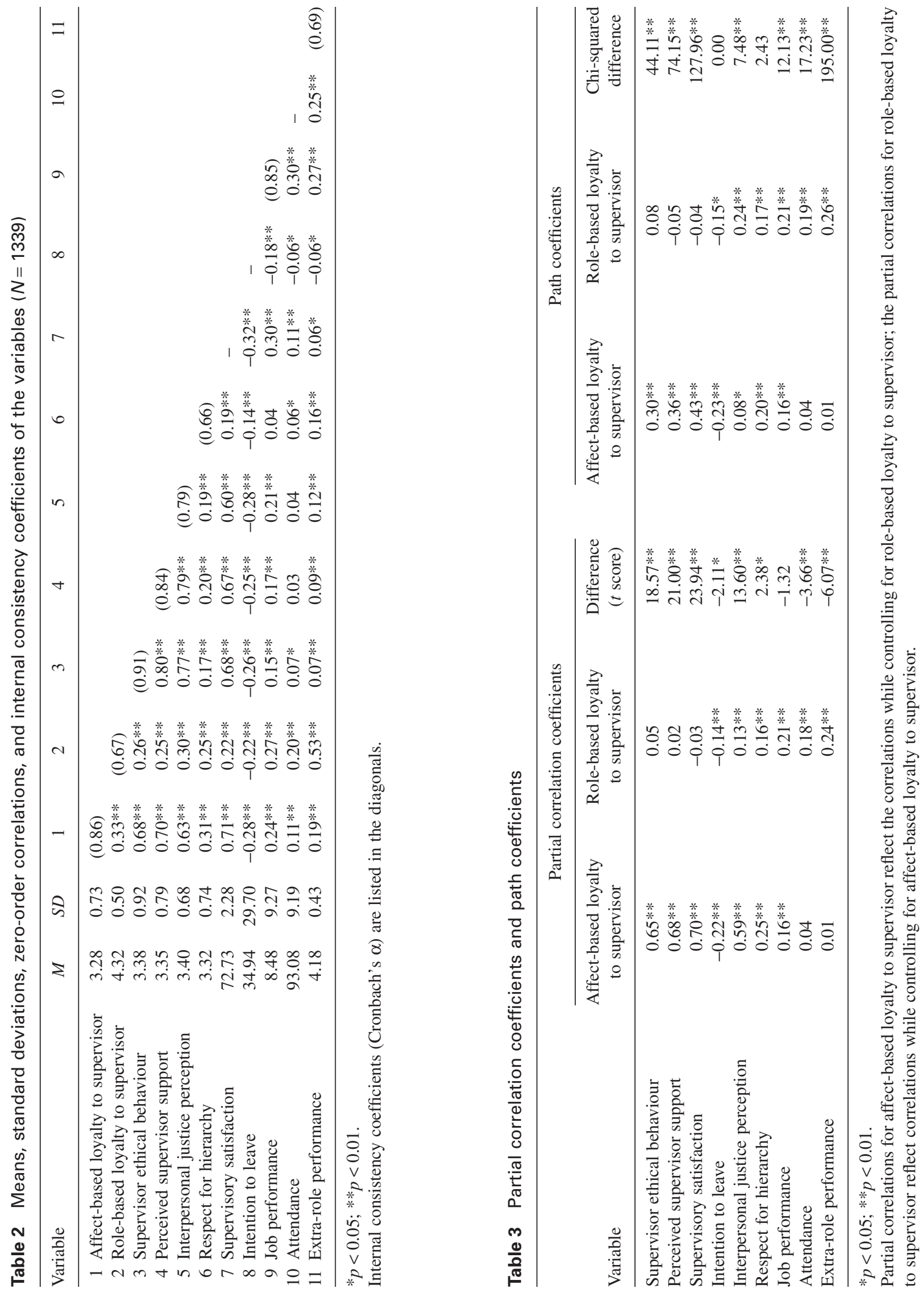
Figure 1 Path analysis of the predictors and outcomes of affect- and rolebased loyalty to the supervisor. Note: $\chi^{2}=66.12, \mathrm{df}=18, \mathrm{NFI}=0.99 ; \mathrm{CFI}=$ $0.99 ; \mathrm{GFI}=0.99 ; \mathrm{SRMR}=0.02 ; \mathrm{RMSEA}$ $=0.05$. This figure does not present the correlation coefficients among the predictor or outcome variables.

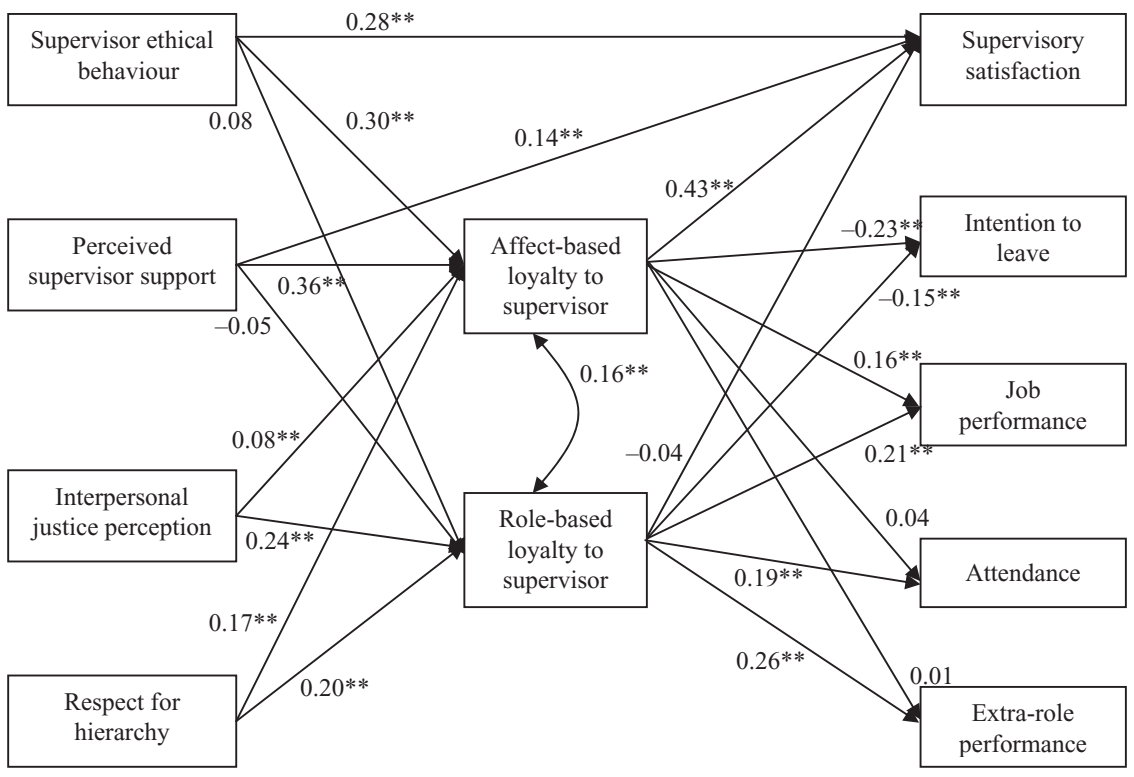

types of loyalty in the path analysis. Thus, the evidence for Hypothesis $3 b$ is mixed.

Job performance had a stronger association with rolebased loyalty than with affect-based loyalty in the path analysis. However, job performance was associated equally strongly with role-based and affect-based loyalty in the partial correlation analysis. Thus, the evidence for Hypothesis $6 \mathrm{a}$ is also mixed. Finally, the two analyses consistently revealed that both attendance $\left(t=-3.66, p<0.01 ; \chi^{2}\right.$ difference $=17.23, \quad p<0.01)$ and extra-role performance $\left(t=-6.07, p<0.01 ; \chi^{2}\right.$ difference $\left.=195.00, p<0.01\right)$ were more strongly associated with role-based loyalty than with affect-based loyalty. These results support Hypotheses $6 \mathrm{~b}$ and $6 \mathrm{c}$.

\section{Discussion}

The present study examined some possible predictors and outcomes of affect- and role-based loyalty. The results show that affect- and role-based loyalty are separate but related constructs. Additionally, the participating employees expressed higher levels of affect-based loyalty when they perceived their supervisors to be ethical, caring, and appreciative. These findings are consistent with recent findings on affective commitment to the supervisor (Stinglhamber \& Vandenberghe, 2003). Respect for hierarchy and interpersonal justice perception had a significant positive association with both role- and affect-based loyalty. That is, employees who perceived a higher level of interpersonal justice and had more respect for hierarchy felt more obligated by their role to remain loyal to their supervisor and identified more strongly with their supervisor.
As expected, affect-based loyalty was more strongly associated with supervisory satisfaction than with rolebased loyalty, which is also consistent with other recent findings (Cheng et al., 2003). Compared with affect-based loyalty, role-based loyalty was strongly related to selfreported extra-role performance and attendance.

Some of the results were inconsistent when different data analysis strategies were used. First, the partial correlation analysis results showed that, compared with rolebased loyalty, affect-based loyalty was more strongly associated with the intention to leave. However, affectand role-based loyalty were associated with the intention to leave to the same extent in the path analysis. Second, job performance had a stronger association with rolebased loyalty than with affect-based loyalty in the path analysis only. A possible explanation for these inconsistent results is that the effects of all of the other variables were not controlled for in the partial correlation analysis as they were in the path analysis.

The current study is limited because it is a crosssectional study and no causal inferences can be drawn from the results. Furthermore, it was conducted in a relatively unstructured Taiwanese business enterprise. Loyalty to the supervisor may not be as important in highly structured organizations, where supervisors have relatively limited influence on the behaviour of employees. Although this study suggests that that role-based loyalty may play an important role in Chinese organizations, the measure of role-based loyalty used is fairly crude, and future studies with a more refined measure of role-based loyalty are necessary. Another direction for future research is to examine how affect- and role-based loyalty are developed and maintained in an organization. 
Although the current study has some limitations, our findings have two important practical implications. First, in Chinese organizations, loyalty to supervisors can be both affect-based and role-based. Our findings suggest that, compared to affect-based loyalty, role-based loyalty is more predictive of extra-role performance and attendance. Therefore, developing and maintaining the role-based loyalty of subordinates may be an effective way of increasing organizational effectiveness. Second, because affect- and rolebased loyalty are related to different aspects of employee effectiveness, organizations may consider promoting both types of loyalty to supervisors.

In conclusion, affect- and role-based loyalty are two separate types of loyalty in Chinese organizations. By identifying factors that are related to these two types of loyalty, this study provides insights into how loyalty to supervisors operates in Chinese organizations.

\section{Acknowledgements}

This study was supported by the National Science Council, Republic of China (94-2752-H-002-003-PAE). The authors wish to thank the Associate Editor Chi Yue Chiu for his support and helpful comments on a draft of this paper.

\section{References}

Becker, T. E., Billings, R. S., Eveleth, D. M. \& Gilbert, N. L. (1996). Foci and bases of employee commitment: Implications for job performance. Academy of Management Journal, 39, S464-S482.

Bies, R. J. \& Moag, J. S. (1986). Interpersonal justice: Communication criteria of fairness. Research on Negotiation in Organizations, 1, 43-55.

Biggart, N. W. \& Hamilton, G. G. (1983). The power of obedience. Administrative Science Quarterly, 29, 541-549.

Chen, Z. X., Tsui, A. S. \& Farh, J. L. (2002). Loyalty to supervisor vs. organizational commitment: Relationships to employee performance in China. Journal of Occupational and Organizational Psychology, 75, 339-356.

Cheng, B. S., Chou, L. F., Huang, M. P., Wu, T. Y. \& Farh, J. L. (2004). Paternalistic leadership and subordinate responses: Establishing a leadership model in Chinese organizations. Asian Journal of Social Psychology, 7, 89-117.

Cheng, B. S., Farh, J. L., Chang, H. F. \& Hsu, W. L. (2002). Guanxi, zhongcheng, competence, and managerial behavior in the Chinese context. Chinese Journal of Psychology, 44, 151-166.

Cheng, B. S. \& Jiang, D. Y. (2000). Supervisory loyalty in Chinese business enterprises: The relative effects of emic and etic constructs on employee effectiveness. Indigenous Psychological Research in Chinese Society, 14, 65-114 (in Chinese).

Cheng, B. S., Jiang, D. Y. \& Riley, J. H. (2003). Organizational commitment, supervisory commitment, and employee outcomes in the Chinese context: Proximal hypothesis or global hypothesis? Journal of Organizational Behavior, 24, 313-334.
Colquitt, J. A. (2001). On the dimensionality of organizational justice: A construct validation of a measure. Journal of Applied Psychology, 86, 386-400.

Cox, T. Jr. (1993). Cultural Diversity in Organizations: Theory, Research, and Practice. San Francisco, CA: Berrett-Koehler.

Eisenberger, R., Stinglhamber, F., Vandenberghe, C., Sucharski, I. L. \& Rhoades, L. (2002). Perceived supervisor support: Contributions to perceived organizational support and employee retention. Journal of Applied Psychology, 87, 565-573.

Elangovan, A. R. \& Shapiro, D. L. (1998). Betrayal of trust in organizations. Academy of Management Review, 23, 547566.

Farh, J. L. \& Cheng, B. S. (2000). A cultural analysis of paternalistic leadership in Chinese organizations. In: J. T. Li, A. S. Tsui $\&$ E. Weldon, eds. Management and Organizations in the Chinese Context. London: Macmillan.

Farh, J. L., Earley, P. C. \& Lin, S. C. (1997). Impetus for action: A cultural analysis of justice and organizational citizenship behavior in Chinese society. Administrative Science Quarterly, 42, 421-444.

Folger, R. \& Bies, R. J. (1989). Managerial responsibilities and procedural justice. Employee Responsibilities and Rights Journal, 2, 79-90.

Greenberg, J. (2006). Losing sleep over organizational injustice: Attenuating insomniac reactions to underpayment inequity with supervisory training in interactional justice. Journal of Applied Psychology, 91, 58-69.

Hamilton, G. G. (1995). The Confucian Dimensions of Industrial East Asia. Cambridge, MA: Harvard University Press.

Hofstede, G. (2001). Culture's Consequences, 2nd edn. Thousand Oaks, CA: Sage Publications.

Hwang, K. K. (1999). Filial piety and loyalty: Two types of social identification in Confucianism. Asian Journal of Social Psychology, 2, 163-183.

Kottke, J. L. \& Sharafinski, C. E. (1988). Measuring perceived supervisory and organizational support. Educational and Psychological Measurement, 48, 1075-1079.

O'Reilly, C. \& Chatman, J. (1986). Organizational commitment and psychological attachment: The effects of compliance, identification, and internalization on prosocial behavior. Journal of Applied Psychology, 71, 492-499.

Podsakoff, P. M., Mackenzie, S. B., Paine, J. B. \& Bachrach, D. G. (2000). Organizational citizenship behaviors: A critical review of the theoretical and empirical literature and suggestions for future research. Journal of Management, 26, 513-563.

Redding, S. G. (1990). The Spirit of Chinese Capitalism. New York, Walter de Gruyter.

Schmacker, R. E. \& Lomax, R. G. (2004). A Beginner's Guide to Structural Equation Modelling, 2nd edn. Mahwah, NJ: Lawrence Erlbaum Association.

Schminke, M., Ambrose, M. L. \& Neubaum, D. O. (2005). The effect of leader moral development on ethical climate and employee attitudes. Organizational Behavior and Human Decision Processes, 97, 135-151.

Shore, L. M., Tetrick, L. E., Taylor, M. S., et al. (2004). The employee-organization relationship: A timely concept in a period of transition. Research in Personnel and Human Resources Management, 23, 291-370. 
Silin, R. H. (1976). Leadership and Value: The Organization of Large-Scale Taiwan Enterprises. Cambridge, MA: Harvard University Press.

Sluss, D. M. \& Ashforth, B. E. (2007). Relational identity and identification: Defining ourselves through work relationships. Academy of Management Review, 32, 9-32.

Spreitzer, G. M., Perttula, K. H. \& Xin, K. (2005). Traditionality matters: An examination of the effectiveness of transformational leadership in the United States and Taiwan. Journal of Organizational Behavior, 26, 205-227.

Stinglhamber, F. \& Vandenberghe, C. (2003). Organizations and supervisors as sources of support and targets of commitment: A longitudinal study. Journal of Organizational Behavior, 24, 251-270.

Wong, C. S. \& Huang, I. C. (2003). The role of perceived quality of social relationships within organizations in Chinese societies. International Journal of Management, 20, 216-222.

Yang, K. S. (1998). Chinese responses to modernization: A psychological analysis. Asian Journal of Social Psychology, 1, 75-97.

Yang, K. S., Yu, A. B. \& Yeh, M. H. (1991). Chinese individual modernity and traditionality: Construct definition and measurement. In: K. S. Yang \& K. K. Hwang, eds. Chinese Psychology and Behavior, pp. 241-306. Taipei: Laureate (in Chinese). 